\title{
Drugs for chronic pain in children: A commentary on clinical practice and the absence of evidence
}

\author{
Marie-Claude Grégoire MSc MD FRCPC, G Allen Finley MD FRCPC FAAP
}

M-C Grégoire, GA Finley. Drugs for chronic pain in children: A commentary on clinical practice and the absence of evidence. Pain Res Manag 2013;18(1):47-50.

Pediatric chronic pain is widespread, under-recognized and undertreated. Best management usually involves a multimodal approach coordinated by a multidisciplinary team. The present commentary specifically discusses common pharmacological approaches to chronic pain in children, identifies gaps in knowledge and suggests several research directions that would benefit future clinical care.

Key Words: Adolescent; Child; Chronic pain; Drug treatment

\section{Les médicaments contre la douleur chronique chez les enfants : un commentaire sur la pratique clinique et l'absence de données probantes}

La douleur chronique est répandue, sous-diagnostiquée et sous-traitée en pédiatrie. La prise en charge exemplaire s'appuie généralement sur une démarche multimodale coordonnée par une équipe multidisciplinaire. Le présent commentaire touche tout particulièrement les démarches pharmacologiques courantes pour traiter la douleur chronique chez les enfants, détermine les lacunes du savoir et propose plusieurs orientations de recherches qui profiteraient aux futurs soins cliniques.
$\mathrm{A}^{\mathrm{h}}$ lthough frequently under-recognized, chronic pain in children and adolescents younger than 19 years of age is widespread. Up to onequarter of children have experienced pain in the past three months, and 'intense and frequent' pain has been reported in $6 \%$ to $8 \%$ of all children $(1,2)$. Pediatric chronic pain is different from adult conditions because the initiating causes and prognoses may be different, and because children are growing and developing throughout the course of the pain. The American Pain Society describes pediatric chronic pain as the "result of a dynamic integration of biological processes, psychological factors, and sociocultural context, considered within a developmental trajectory. This category of pain includes persistent (ongoing) and recurrent (episodic) pain with possible fluctuations in severity, quality, regularity, and predictability" (3). Chronic pain in children can have a profound impact extending beyond the current suffering. Children with chronic pain frequently miss long periods of school and have difficulty maintaining social contacts and development. Families of children with pain are also significantly affected because a parent may have to stay home with a child who is not attending school (4).

The present commentary is intended to provide a real-life, pragmatic perspective on the usual pharmacological approaches used by clinicians for common problems encountered in pediatric chronic pain clinics in North America and Europe. Current recommended options are mainly based on clinicians' expertise and experience. The present commentary will aim to emphasize the lack of high-grade research evidence for these treatment strategies and the unfortunate but inevitable frequent off-label use of medications. We also offer a plea and a suggested agenda for pharmacological research specific to children, to support the establishment of logical and evidence-informed treatment guidelines for children and adolescents everywhere.

\section{PEDIATRIC CHRONIC PAIN}

Children and adolescents can be affected by chronic diseases, such as arthritis, cancer, sickle cell disease and endometriosis, that may result in continuing tissue inflammation and, therefore, nociceptive pain. These diseases can also trigger peripheral or central sensitization, causing pain that continues after the tissue injury has healed. Children with severe neurological impairment (cerebral palsy, neurodegenerative diseases, autism, etc) may also experience chronic pain due to either their primary condition or repeated surgical procedures. These individuals may not receive adequate treatment due to communication difficulties, yet are often excluded from clinical trials $(5,6)$.
There are also a number of common pediatric chronic pain syndromes that are not associated with a particular disease (7). These syndromes may have a neuropathic or central sensitization contribution, but the mechanisms have not been adequately elucidated. Fibromyalgia, recurrent abdominal pain (eg, visceral hyperalgesia associated with irritable bowel syndrome or inflammatory bowel disease) and 'chronic widespread pain' all fit within this category. Chronic or recurrent headache may result from a combination of mechanisms, including neuropathic, inflammatory and vascular processes, and treatment is still based on consensus only (8).

Similar to adults, children may suffer from neuropathic pain or neuralgia resulting from nerve injury during surgery or trauma, nerve entrapment or inflammation of the peripheral nervous system from infection, toxicity (eg, following chemotherapy), immune or metabolic disorders. These would be considered obvious and clear-cut examples of neuropathic pain that generally present with burning and/or lancinating pain, and allodynia, hyperesthesia or dysesthesia. This type of pain usually, but not always, occurs in a recognizable peripheral nerve distribution. Complex regional pain syndrome type I has similar pain symptomatology, but the mechanism remains poorly understood and there may be associated autonomic dysfunction. The distribution of pain may not follow recognized nerve pathways (9).

DRUGS CURRENTLY USED IN CLINICAL PRACTICE It is well accepted in the field of pain medicine that optimal management of chronic pain in children or adults should involve a multidisciplinary team and multimodal therapy, including psychological and physical methods. A comprehensive pediatric pain team often includes a physician (pediatrician or anesthesiologist), an advanced practice nurse, a clinical psychologist, a physiotherapist and other professionals such as social workers and occupational therapists. However, the present commentary focuses only on available pharmacological treatments and is written primarily from the perspective of Canadian drug availability.

As a disclaimer, it should be made clear that many of the drugs used in pediatric care have not been licensed either for pediatric use or for the specific pain indication for which they are used. This is one of the major deficiencies in the tools available to the clinician. Many clinicians make treatment decisions based on personal communication during discussions at meetings or extrapolation from adult practice. There are currently no published guidelines or treatment algorithms 
for neuropathic pain in children, although some specific diseases have treatment guidelines and the WHO recently released guidelines on the pharmacological treatment of persisting pain in children with medical illnesses (10). Pediatric chronic pain reviews published in the past decade consistently conclude that 'rigorous randomized clinical trials (RCTs) are needed' (11).

Acetaminophen, nonsteroidal anti-inflammatory drugs, coxibs Acetaminophen (paracetamol) remains a staple of over-the-counter analgesic treatment. Most patients who present to a chronic pain clinic will have tried various doses, usually with little benefit. Despite acetaminophen being a universal first-line pain treatment, no RCT has ever been published for a chronic pain indication in children. Patients will also frequently have tried common over-the-counter nonsteroidal anti-inflammatory drugs (NSAIDs), such as ibuprofen, but rarely as a regular dose. Patients are often heard to say "I tried it once or twice, but it didn't work". Even when the mechanism causing the pain is clearly inflammatory, patients may not have taken an antiinflammatory drug consistently for a sufficiently long period to achieve an anti-inflammatory effect. A recent review on ibuprofen mentions that, in adults, ibuprofen is similar to other NSAIDs and to coxibs in terms of efficacy, but as with other NSAIDs, this efficacy decreases with extended use (six months or more). There were no recommendations to use ibuprofen on a long-term basis for children (12).

The only published pediatric RCT of celecoxib involved the treatment of juvenile rheumatoid arthritis, and showed that $3 \mathrm{mg} / \mathrm{kg}$ or $6 \mathrm{mg} / \mathrm{kg}$ twice per day was equally as effective as $7.5 \mathrm{mg} / \mathrm{kg}$ naproxen twice per day over a 12 -week period (13). There were no differences in the gastrointestinal side effects between the two medications. Anecdotally, many clinicians (and patients) believed that rofecoxib was significantly more effective than celecoxib, but no comparative studies involving pediatric patients were completed before rofecoxib was withdrawn from the market.

\section{Anticonvulsants}

Gabapentin and pregabalin, two gamma-aminobutyric acid analogues, have become popular drugs for the treatment of neuralgia and specific peripheral neuropathies, including phantom limb pain, and for some genetic and metabolic disorders (Fabry disease, Charcot-Marie-Tooth neuropathy type 2, etc), as well as less well-defined conditions such as fibromyalgia, visceral hyperalgesia and chronic daily headache. There are a number of small case series that have reported promising results $(14,15)$. Pregabalin was also effective for chemotherapy-related neuropathic pain in a small open-label pediatric study (16), but no controlled trials of these drugs have been performed in children or adolescents. A single-dose study of gabapentin showed that children one month to five years of age require approximately $30 \%$ higher daily doses of gabapentin than adults (17). In spite of recent revelations concerning questionable marketing techniques and unreported industry-sponsored research (18), most clinicians can describe cases in which gabapentin has been clearly and dramatically effective, and others in which incapacitating side effects or lack of efficacy make it a less attractive treatment approach. The most significant challenge is predicting which patient group will respond to these drugs.

There is a long history of use of carbemazepine and other anticonvulsants for treatment of childhood epilepsy, but these are now third- or fourth-line drugs for neuropathic pain in adults (except for trigeminal neuralgia, which is almost nonexistent in children) (19). These drugs have significant side effects and monitoring requirements; therefore, it is difficult to justify their use as primary agents in pediatric pain. A review by Golden et al (20) in 2006 concluded that there was insufficient evidence to make recommendations regarding the use of these medications for pediatric neuropathic pain.

\section{Antidepressants}

Tricyclic antidepressants are a mainstay of neuropathic pain treatment and are considered to be first-line drugs in adult practice (19). They are also used in pediatrics, but again without much published evidence. In fact, some low-dose controlled studies $(21,22)$ and a Cochrane review
(23) have failed to support their effectiveness in treating pediatric chronic pain. Clinical practice for the use of these medications varies as well, with daily oral doses of amitriptyline or nortriptyline ranging from $0.2 \mathrm{mg} / \mathrm{kg}$ to $4 \mathrm{mg} / \mathrm{kg}$.

Duloxetine has been shown to help with fibromyalgia-related stiffness (24) and is also indicated in some neuropathies in adults, but is not labelled for pediatric use.

\section{Opioids}

Opioids are used relatively infrequently in children with chronic nonmalignant pain (25), but are used extensively for cancer and other persisting pain in which there is continuing tissue damage. However, there is no evidence for the benefit of one opioid over another, or for opioids compared with other drugs or drug combinations in pediatric chronic pain syndromes. A 2007 review by Zernikow et al (26) on the use of transdermal fentanyl in pediatrics commented on the lack of RCTs or controlled cohort studies. Only rare safety studies have been published on the long-term use of opioids and related compounds in children and adolescents $(27,28)$. Methadone, a $\mu$-opioid agonist and $\mathrm{N}$-methyl-D-aspartic acid antagonist, has shown potential as a treatment for complex pediatric pain, especially when there is a neuropathic component, but has mostly been studied open-label in children with advanced cancer (29). Methadone has a long half-life and wide variations in dosing for clinical effect, which makes it complex to use safely.

\section{Others}

Finally, there are a number of drug classes that have been tried in clinical practice with little basis in clinical research, but with some logical and mechanistic rationale. These include alpha-2 adrenergic agonists, such as clonidine and, recently, dexmedetomidine, but the only reported trials for pediatric chronic pain (in this case, headache) were not positive $(30,31)$. A Cochrane review concluded that there is no preventive effect of clonidine on pediatric headache (32). Lidocaine (intravenously or transdermally administered) and the related sodium channel blocker mexilitine (orally administered) are also rarely used in pediatric pain, and only case reports have been published $(33,34)$.

Pamidronate, a bisphosphonate, has been described in case series as useful for children with neurological conditions and chronic recurrent multifocal osteomyelitis, by reducing pain caused by fractures (35). There is no evidence to support its routine use in chronic pain without osteopenia.

Cannabinoid use has been described in adolescent case studies (36). Increasing interest in the pediatric use of Sativex (tetrahydrocannabinol-cannabidiolcombination;BW Pharmaceuticals, United Kingdom) is expected in coming years, although published reports of pediatric applications are lacking. In Canada, Sativex is currently labelled only for the relief of pain in adults with specific severe neuropathic pain syndromes (multiple sclerosis and advanced cancer), and is not available at all in most countries (37).

Anesthesiologists, who direct many pediatric chronic pain clinics, are familiar with the short-term use of ketamine, an $\mathrm{N}$-methyl-D-aspartic acid antagonist. It is, therefore, understandable that its use in chronic pain management has increased in recent years. There is no oral form of ketamine, however, so clinicians have used the injectable form by mouth, and the dosage administered is fairly arbitrary in the absence of guidelines. In addition, there has been no research on long-term use, although there have been suggestions of disturbing dose/duration-dependent side effects, including cystitis $(38,39)$.

\section{RESEARCH AGENDA}

We believe the preceding examples demonstrate the significant gaps in research on the pharmacology of chronic and complex pediatric pain. We suggest a number of areas in which the expertise of researchers could have a significant impact on clinical care of children and adolescents. The following priority list covers a limited number of critical issues; the lack of research for pediatric medications extends beyond the field of chronic pain, as presented recently in an editorial (40). 
- Pharmacokinetics and pharmacodynamics must be determined in infants and children for most of the drugs listed above, including in children with complex medical conditions, with special attention devoted to potential interactions and cumulative side effects. Until these studies are available, it will not be possible to know the safe and effective dosage for these medications.

- Some classes of medications, including the anticonvulsants and antidepressants, have only been studied in children for their original target conditions. Pediatric pain studies involving these medications are clearly necessary. Among other things, it is important to understand why two patients with very similar clinical signs and symptoms can have dramatically different responses to drugs such as gabapentin, pregabalin and amitriptyline. Are there significant pharmacogenetic variations in response or metabolism?

- Strategic knowledge translation needs to occur when practice changes are recommended by research evidence. For example, codeine is still widely used in Canada and other countries, in spite of the well-known pharmacogenetic issues associated with its metabolism (41-43) and recommendations to stop its use (44).

Finally, we recognize that RCTs may not be the best methodology for treatment studies in low-frequency pediatric chronic and complex pain conditions. Guidelines for outcome measures in pediatric pain trials have already been defined by the Pediatric Initiative on Methods, Measurements and Pain Assessment in Clinical Trials (PedIMMPACT) consensus group (45) and were recently reviewed in a report from a United States Food and Drug Administration workshop (46). More creative approaches to trial design, such as n-of- 1 trials or

\section{REFERENCES}

1. Perquin CW, Hazebroek-Kampschreur AAJM, Hunfeld JAM, et al. Pain in children and adolescents: A common experience. Pain 2000;87:51-8.

2. van Dijk A, McGrath PA, Pickett W, VanDenKerkhof EG. Pain prevalence in nine- to 13 -year-old schoolchildren. Pain Res Manag 2006;11:234-40.

3. American Pain Society. Pediatric chronic pain. APS Bulletin 2001;11 <www.ampainsoc.org/library/bulletin/jan01/posi1.htm> (Accessed April 30, 2012).

4. Brown RT. Managing pediatric pain at school. In: Finley GA, McGrath PJ, Chambers CT, eds. Bringing Pain Relief to Children: Treatment Approaches. Totowa: Humana Press, 2006:113-30.

5. Parkinson KN, Gibson L, Dickinson HO, Colver AF. Pain in children with cerebral palsy: A cross-sectional multicentre European study. Acta Paediatr 2010;99:446-51.

6. Breau LM, Camfield CS, McGrath PJ, Finley GA. The incidence of pain in children with severe cognitive impairments. Arch Pediatr Adolesc Med 2003;157:1219-26.

7. King S, Chambers CT, Huguet A, et al. The epidemiology of chronic pain in children and adolescents revisited: A systematic review. Pain 2011;152:2729-38.

8. Seshia SS. Chronic daily headache in children and adolescents. Curr Pain Headache Rep 2012;16:60-72.

9. Walco GA, Dworkin RH, Krane EJ, LeBel AA, Treede RD, Neuropathic pain in children: Special considerations. Mayo Clin Proc 2010;85:S33-S41.

10. World Health Organization: WHO guidelines on the pharmacological treatment of persisting pain in children with medical illnesses. Geneva: World Health Organization, 2012.

11. Walker SM. Pain in children: Recent advances and ongoing challenges. Br J Anaesth 2008;101:101-10.

12. Rainsford KD. Ibuprofen: Pharmacology, efficacy and safety. Inflammopharmacology 2009;17:275-342.

13. Foeldvari I, Szer IS, Zemel LS, et al. A prospective study comparing celecoxib with naproxen in children with juvenile rheumatoid arthritis. J Rheumatol 2009;36:174-82.

14. Butkovic D, Toljan S, Mihovilovic-Novak B. Experience with gabapentin for neuropathic pain in adolescents: Report of five cases. Paediatr Anaesth 2006;16:325-9.

15. Rusy LM, Troshynski TJ, Weisman SJ. Gabapentin in phantom limb pain management in children and young adults: Report of seven cases. J Pain Symptom Manage 2001;21:78-82. crossover trials, are encouraged to elucidate treatment effects in pediatric fibromyalgia, neuropathic pain, visceral hyperalgesia, complex regional pain syndrome and other conditions. $\mathrm{N}$-of- 1 trials are randomized, double-blinded, multiple crossover comparisons of an intervention and a control treatment in a single patient with a relatively stable condition. They are particularly useful when recruiting large numbers of patients is difficult or not possible $(47,48)$. In crossover trials, one-half of the participants begin with the studied treatment then switch to the control treatment, and vice versa for the other one-half of the participants. This design helps to lower the number of required participants and confounding biases, but may be difficult to apply when studying medications with long carry-over effects (49). In addition to these alternative study designs, immediate rescue with nurse-controlled analgesia or patient-controlled analgesia, using analgesic sparing as the primary efficacy endpoint instead of pain scores, was proposed as a different analgesic trial design in the recent United States Food and Drug Administration workshop (46). Such a design allows both blinding and appropriate treatment of pain by a catch-up effect in the placebo group through the use of patient-controlled or nurse-controlled analgesia.

This is an opportunity for fruitful collaboration between pharmacologists and pediatric pain clinicians to create evidence-based science that will have a significant clinical impact on the treatment of chronic and complex pediatric pain. Who is ready to take up the challenge?

CONFLICTS OF INTEREST: The authors declare no conflicts of interest regarding this article.

16. Vondracek P, Oslejskova H, Kepak T, et al. Efficacy of pregabalin in neuropathic pain in paediatric oncological patients. Eur J Paediatr Neurol 2009;13:332-6.

17. Haig GM, Bockbrader HN, Wesche DL, et al. Single-dose gabapentin pharmacokinetics and safety in healthy infants and children. J Clin Pharmacol 2001;41:507-14.

18. Vedula SS, Bero L, Scherer RW, Dickersin K. Outcome reporting in industry-sponsored trials of gabapentin for off-label use. N Engl J Med 2009;361:1963-71.

19. Moulin DE, Clark AJ, Gilron I, et al. Pharmacological management of chronic neuropathic pain - consensus statement and guidelines from the Canadian Pain Society. Pain Res Manag 2007;12:13-21.

20. Golden AS, Haut SR, Moshé SL. Nonepileptic uses of antiepileptic drugs in children and adolescents. Pediatr Neurol 2006;34:421-32.

21. Saps M, Youssef N, Miranda A, et al. Multicenter, randomized, placebo-controlled trial of amitriptyline in children with functional gastrointestinal disorders. Gastroenterology 2009;137:1261-9.

22. Huber AM, Tomlinson GA, Koren G, Feldman BM. Amitriptyline to relieve pain in juvenile idiopathic arthritis: A pilot study using Bayesian meta-analysis of multiple $\mathrm{N}$-of-1 clinical trials. J Rheumatol 2007;34:1125-32.

23. Kaminski A, Kamper A, Thaler K, Chapman A, Gartlehner G. Antidepressants for the treatment of abdominal pain-related functional gastrointestinal disorders in children and adolescents. Cochrane Database Syst Rev 2011;(6):CD008013.

24. Bennett R, Russell IJ, Choy E, et al. Evaluation of patient-rated stiffness associated with fibromyalgia: A post-hoc analysis of 4 pooled, randomized clinical trials of duloxetine. Clin Ther 2012;34:824-37.

25. Slater ME, De Lima J, Campbell K, Lane L, Collins J. Opioids for the management of severe chronic nonmalignant pain in children: A retrospective 1-year practice survey in a children's hospital. Pain Med 2010;11:207-14.

26. Zernikow B, Michel E, Anderson B. Transdermal fentanyl in childhood and adolescence: A comprehensive literature review. J Pain 2007;8:187-207.

27. Finkel JC, Finley A, Greco C, Weisman SJ, Zeltzer L. Transdermal fentanyl in the management of children with chronic severe pain: Results from an international study. Cancer 2005;104:2847-57.

28. Rose JB, Finkel JC, Arquedas-Mohs A, et al. Oral tramadol for the treatment of pain of 7-30 days' duration in children. Anesth Analg 2003;96:78-81. 
29. Davies D, DeVlaming D, Haines C. Methadone analgesia for children with advanced cancer. Pediatr Blood Cancer 2008;51:393-7.

30. Sillanpää M. Clonidine prophylaxis of childhood migraine and other vascular headache. A double blind study of 57 children. Headache 1977;17:28-31.

31. Sills M, Congdon P, Forsythe I. Clonidine and childhood migraine: A pilot and double-blind study. Dev Med Child Neurol 1982;24:837-41.

32. Victor S, Ryan SW. Drugs for preventing migraine headaches in children. Cochrane Database Syst Rev 2003;(4):CD002761.

33. Nathan A, Rose JB, Guite JW, Hehir D, Milovcich K. Primary erythromelalgia in a child responding to intravenous lidocaine and oral mexiletine treatment. Pediatrics 2005;115:e504-e507.

34. Nayak S, Cunliffe M. Lidocaine 5\% patch for localized chronic neuropathic pain in adolescents: Report of five cases. Paediatr Anaesth 2008;18:554-8.

35. Howe W, Davis E, Valentine J. Pamidronate improves pain, wellbeing, fracture rate and bone density in 14 children and adolescents with chronic neurological conditions. Dev Neurorehabil 2010;13:31-6.

36. Rudich Z, Stinson J, Jeavons M, Brown SC. Treatment of chronic intractable neuropathic pain with dronabinol: Case report of two adolescents. Pain Res Manag 2003;8:221-4.

37. Health Canada. < www.hc-sc.gc.ca/dhp-mps/marihuana/howcomment/medpract/infoprof/index-eng.php\#a4_5> (Accessed April 30, 2012).

38. Grégoire MC, MacLellan DL, Finley GA. A pediatric case of ketamine-associated cystitis (Letter-to-the-Editor RE: Shahani R, Streutker C, Dickson B, et al: Ketamine-associated ulcerative cystitis: A new clinical entity. Urology 2007;69:810-2). Urology 2008;71:1232-3.
39. Morgan CJ, Curran HV. Ketamine use: A review. Addiction 2012;107:27-38.

40. Peterson B, Hébert PC, MacDonald N, Rosenfield D, Stanbrook MB, Flegel K. Industry's neglect of prescribing information for children. CMAJ 2011;183:994-5.

41. Voronov P, Przybylo HJ, Jagannathan N. Apnea in a child after oral codeine: A genetic variant - an ultra-rapid metabolizer. Paediatr Anaesth 2007;17:684-7.

43. Williams DG, Patel A, Howard RF. Pharmacogenetics of codeine metabolism in an urban population of children and its implications for analgesic reliability. Br J Anaesth 2002;89:839-45.

43. Kelly LE, Rieder M, van den Anker J, et al. More codeine fatalities after tonsillectomy in North American children. Pediatrics 2012;129:e1343-7

44. MacDonald N, MacLeod SM. Has the time come to phase out codeine? CMAJ 2010;182:1825

45. McGrath PJ, Walco GA, Turk DC, et al. Core outcome domains and measures for pediatric acute and chronic/recurrent pain clinical trials: PedIMMPACT recommendations. J Pain 2008;9:771-83.

46. Berde CB, Walco GA, Krane EJ, et al. Pediatric analgesic clinical trial designs, measures, and extrapolation: Report of an FDA scientific workshop. Pediatrics 2012;129;354

47. Gabler NB, Duan N, Vohra S, Kravitz RL. N-of-1 trials in the medical literature: A systematic review. Med Care 2011;49:761-8.

48. Nikles J, Mitchell GK, Schluter P, et al. Aggregating single patient ( $\mathrm{n}$-of-1) trials in populations where recruitment and retention was difficult: The case of palliative care. J Clin Epidemiol 2011;64:471-80.

49. Grady D, Cummings SR, Hulley SB. Designing an experiment: Clinical trials II. In Hulley SB, Cummings SR, Browner WS, Grady D, Hearst N, Newman TB, eds. Designing Clinical Research. Philadelphia: Lippincott Williams \& Wilkins, 2001:168-70. 


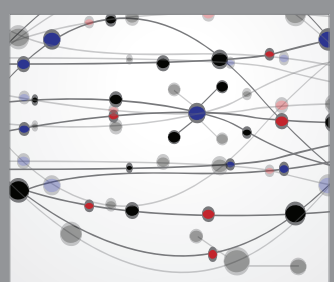

The Scientific World Journal
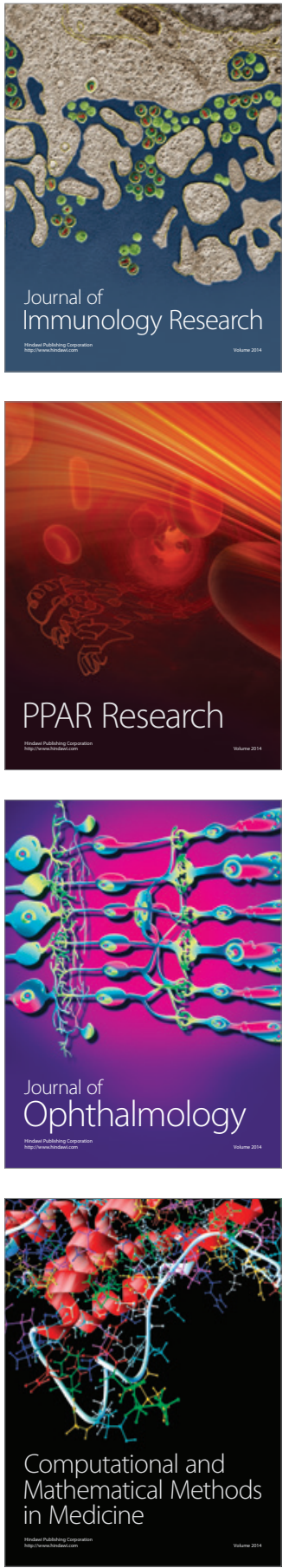

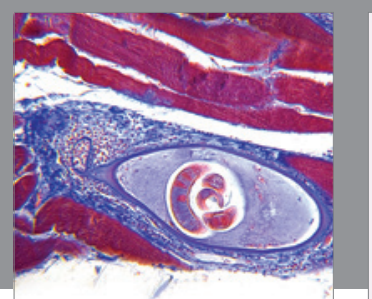

Gastroenterology Research and Practice

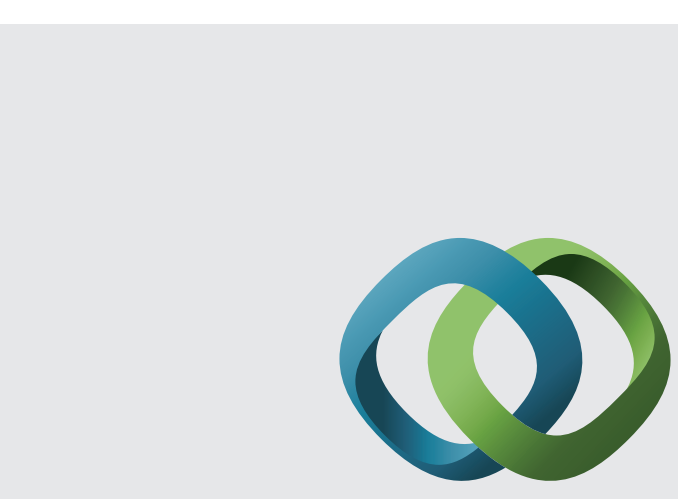

\section{Hindawi}

Submit your manuscripts at

http://www.hindawi.com
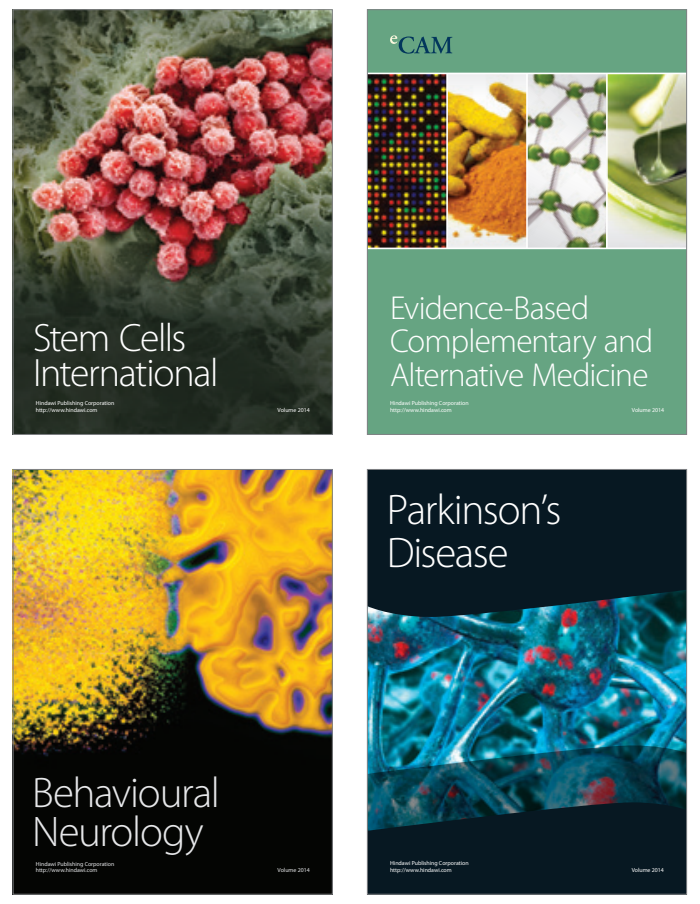
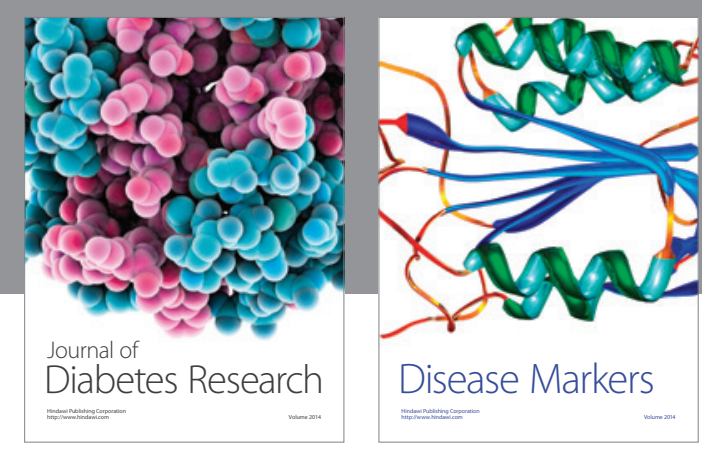

Disease Markers
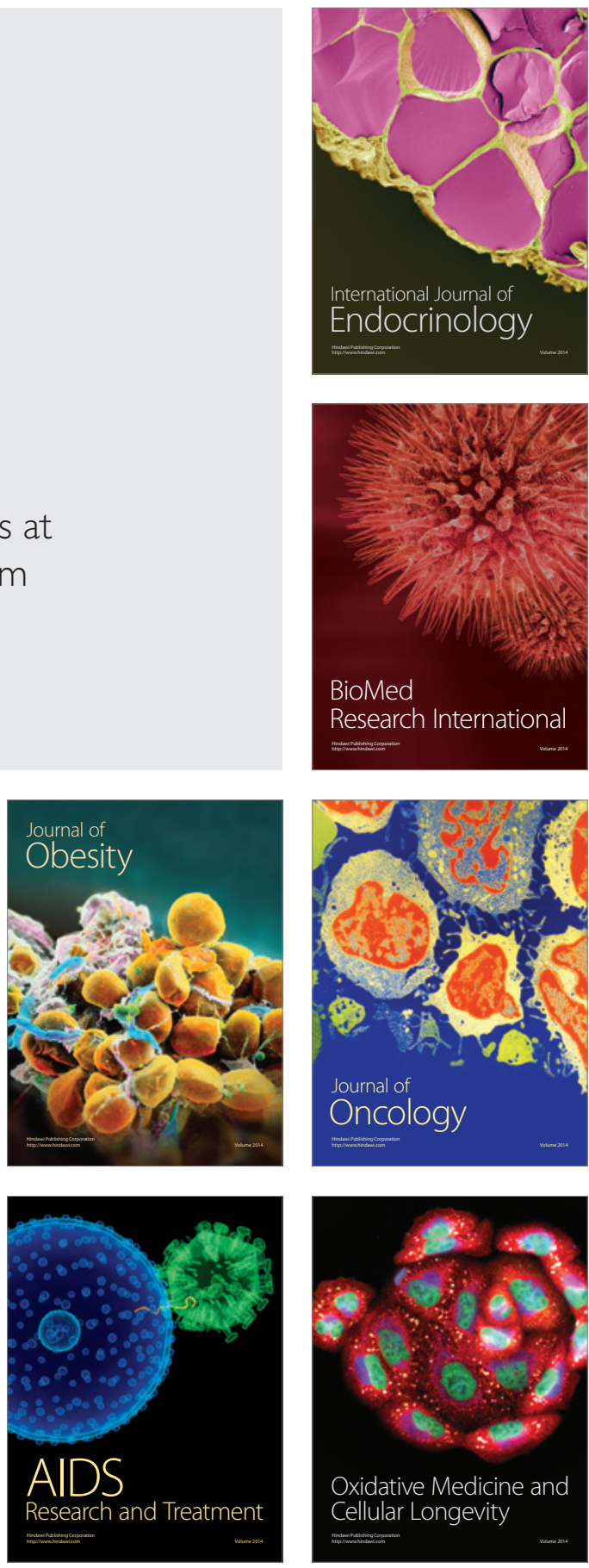